\section{PROGRESS IN AERONAUTICS*}

\author{
BY SIR BEN LOCKSPEISER \\ Ministry of Aircraft Production
}

$I^{\mathrm{T}}$ is just over forty years since the Wright Brothers flew at Dayton and fulfilled a dream that man had cherished throughout the ages. During the last three months of 1945 , in large-scale trooping operations following the end of the Second World War, R.A.F. Transport Command flew 20,000 men back to England from the Far East ; while American Transport Command in the summer of 1945 flew 5,0006,000 men a month across the Atlantic. These few sentences give the measure of aeronautical progress, impressive by any standard.

\section{Evolution of Structural Design of Aircraft}

Many minds, many sciences, many industries have made this achievement possible. The typical aeroplane has evolved during the last thirty years from a wooden skeleton covered in fabric. Increase in speeds made the drag of external struts and bracing prohibitive and the distortion of fabric under aerodynamic pressure unacceptable. Heavier wing loadings turned designers towards light alloys. The constant urge to keep down drag led to retractable undercarriages, reduction of body-size and elimination of equipment carried in the airstream. Space became as serious a preoceupation as weight and the wing space was utilized to the full for stowing wheels, housing fuel tanks and for the carriage of any part of the load which the skill of the designer could place there. So we have arrived at the modern streamline monoplane built up of hollow shells in duralumin, of which the Tudor, a civil transport type, is a typical example.

In steady horizontal flight the lift on the wings is roughly equal to the weight of the aircraft, the tailplane carrying a small load to maintain equilibrium in pitch, but either deliberately by the execution of manœuvre by the pilot or fortuitously by atmospheric gusts, the wings may be loaded to several times the aircraft weight. By violent use a pilot can break up any aeroplane in the air, and it is necessary for designers to know what loads are actually or likely to be encountered in flight. In comparable land-based problems additional structural strength can usually be obtained by increased weight without any great difficulty. But the aircraft designer is brought up in a very hard school. He knows that every pound weight put into the structure robs the payload of a pound, and he very properly asks for exact knowledge on which to base his design.

For this purpose it is necessary to know both the acceleration normal to the flight path and the forward speed at the same instant. From these the aerodynamics and load distribution can be deduced. This information is provided by an instrument called a $V \cdot g$ recorder which gives a continuous plot of acceleration against air speed. These recorders, which are left in the aeroplane for long periods, were fitted to a large number of Service aircraft during the War, and records were obtained over hundreds of hours of flying. Statistical analysis of these records has enabled load-factor scales to be established according to the aircraft size, duty and speed.

The importance of exact information of this nature in relation to atmospheric gusts can be appreciated from the fact that in the case of the new civil air.

* Friday evening discourse at the Royal Institution delivered on March 29. liner, Brabazon $\mathrm{I}$, increased structure weight to withstand gusts of a vertical velocity of $50 \mathrm{ft}$. $/ \mathrm{sec}$. would have entailed a pay-load penalty of 3.5 tons.

\section{Reduction of Drag}

The parasitic drag of aircraft having been largely eliminated by the revolution in structural design, a constant urge to reduce drag has caused much attention to be devoted in recent years to a detailed study of a fundamental character, of the nature of air flow around aerofoils, or wings, with important consequences to the further reduction of drag.

These investigations show that when air flows over an aircraft wing surface at speeds at which air behaves substantially as though it were an incom. pressible fluid, it may do so in one of two ways. In one type of flow the wing as it speeds through the air drags a thin layer of air with it as though this layer were composed of a pack of very thin cards. The lowest card moves with the wing and each card drags and slips past its neighbour, the top card of the layer remaining at rest. This particular type of flow is called laminar flow. The actual layer affected, the so-called 'boundary layer', is itself comparatively thin, and the air above is quite unaffected.

In the other type of flow, called turbulent flow, the air is set in rotational or eddying motion. This mixes up the air and causes a considerable increase in drag. Turbulence, in fact, is a means of wasting energy.

But the most serious cause of loss of energy arises when the air separates from the surface. This separation may occur in laminar or turbulent flow. Instead of the streamlines running in a direction parallel to the wing, they depart from it at an angle and cause a large-scale irregular turbulence which builds up to a wide wake and causes a large increase in drag.

The drag of a wing with laminar flow around it is generally many times smaller than one in which separation occurs, particularly when the separation point is well forward. If it were possible to produce laminar flow over the whole surface the least possible drag would be obtained and the least possible price paid in getting the wing through the air. It would then slip through the air in the same way as a piece of wet soap slips through the fingers.

\section{Laminar Flow Wings}

We know how to obtain laminar flow over a large part of wing surfaces and we have achieved it both in the wind tunnel and in flight. The conditions required are threefold. First, the air through which the aircraft flies must itself be free from turbulence; secondly, the pressure conditions along the wing must be favourable, that is, the pressure must fall steadily ; and thirdly, the surface of the wing or body must be very smooth and free from waviness. The third condition is very exacting, as the surface smoothness must be equivalent to that of writing paper, and any waviness of the surface must. be restricted to one or two thousandths of an inch in 2 inches, measured in the direction from leading to trailing edge of the wing. Rather more waviness can be tolerated in the direction along the span.

Fortunately, the first condition is always satisfied in free air, which is much better in this respect than the best wind tunnel. We know how to satisfy the second condition over a large part of the surface by providing wing sections of special shape. This is a problem which has been solved by mathematical methods, and a group of very able mathematicians 
in Britain has made outstanding contributions to this work. The third condition is a question of manufacture and maintenance. Difficult problems are involved, but our designers and manufacturers have already gone a long way towards solving them.

The difficulty of maintaining so true a wing surface in flight is increased by the liability of the wing to pick up, at low altitude, dust particles and insects which are frequently sufficiently large to cause local breakdown of the laminar flow to the turbulent form. This problem has been studied in flight at the Royal Aircraft Establishment by an ingenious method which results in dark patches upon the wing surface where the air flow is turbulent but not where it is laminar.

Fortunately, the upper atmosphere is normally free from both turbulence and foreign bodies, and the practical problem for the future consists in protecting the wing surface during take-off and climb to operating altitude. The sacrifice of the advantages of laminar flow during this period is of little consequence, and a solution of this problem is now being actively sought.

\section{Wing Suction}

It has not been possible to obtain laminar flow, even experimentally, over the whole of the wing surface, although we have been successful over the larger part. It is not possible to maintain a falling pressure gradient over the whole of the wing profile; at some point towards the rear, the laminar type of flow changes to the turbulent variety, which may break away from the surface of the wing and give rise to a turbulent wake. We are not likely to succeed by cunning aerodynamic shapes and skilful manufacture alone. It may be necessary to supplement these by providing suction slots on the wing surface to divert a part or whole of the air boundary layer into the wing to provide a more desirable type of air flow. Wing suction will probably play an important part in the evolution of the wing design of the future. Flight with heavier-than-air craft is only possible because of the existence of aerofoils (that is, shaped bodies) the lift of which is many times greater than their drag; and in the ceaseless quest to maximize lift and minimize drag, control of the boundary layer by suction or even by blowing will probably play a significant part. The aircraft wing of the future, relying perhaps as much on the partial removal or the reinforcement of the air boundary layer as on the shape itself for controlling the air flow, will no doubt be a more complex affair than present-day wings. A price will, of course, have to be paid for this complication, but as it is hoped eventually to obtain a wing drag of not more than about one-third of what is now common, the price should be well worth paying.

\section{Tailless and All-Wing Aircraft}

It is not at all easy, indeed it may be impossible, to treat the body or fuselage in the same way, and this leads directly to the conclusion that for very low drag, aircraft for speeds not comparable with the speed of sound should be built either with bodies of greatly reduced size or better still without bodies and tailplanes. We thus arrive inevitably at the conception of the tailless aircraft, of which the glider constructed by Armstrong Whitworth is a typical example. The function of the tail of a conventional aircraft in providing the necessary elements of stability and control is fulfilled in the tailless aircraft by sharply sweeping back the wings and fitting what are called 'elevons' to the rear outer part of the wings. These are used differentially as ailerons to control the aircraft in roll or in unison as elevators to control it in pitch.

Pressing this line of thought to its limit, it should be possible to do away with the body altogether and arrive at the conception of an all-wing aircraft large enough to house the pilot, crew and passengers in the wing. Apart from the low-drag possibilities of such an aircraft driven by jet propulsion, it is likely to show a considerable saving in structure-weight over the conventional type in the very large sizes, say those more than 100 tons. This, of course, is only the technical side of the story. The degree of comfort which it is possible to provide in an all-wing aireraft may not be acceptable, but I believe that this disability, if it exists at all, will not operate for night flying. Sleeping berths in a wing can be made every bit as comfortable as those in a conventional aircraft body, and I think it very likely that fast long-distance all-wing civil aireraft will emerge as the best type of aircraft for night passengers and mails. Long-range flight on the main trunk routes of the world demands the highest practical cruising speeds, the aim being to connect the principal capitals of the world by overnight service. This means high speeds both to take account of headwinds, which may be up to 100 miles an hour on the North Atlantic, and to compensate for loss of clock-time when travelling in an eastward direction.

\section{Consequences of Flying at the Speed of Sound}

Implicit in the theory underlying the achievement of low drag is the conception of air as an incompress. ible fluid, and for bodies moving at speeds below and not comparable with the speed of sound this conception is substantially true in practice. The velocity of sound in air at sea-level is about 760 m.p.h., and the effect of the compressibility begins to make itself sensibly felt above about 500 m.p.h. The effect of compressibility is to produce an increased drag rapidly increasing with rising speed and reaching, at the speed of sound, a value many times greater than would be encountered under conditions of in. compressible flow.

It is not immediately obvious why the speed of sound should play such a dominating and decisive part, and perhaps a few words from a purely physical aspect will not be out of place.

The air flow past an aerofoil at a speed well below the speed of sound or, as it is called, a low subsonic speed, conforms to a smooth flow pattern which extends forward of the aerofoil. The air ahead of the aerofoil is prepared in advance for its arrival, part being accelerated to flow over the upper surface and part over the lower surface. Clearly, the moving aerofoil possesses as it were a signalling system to warn the air ahead of its approach and allow it to take full advantage of its shape to slip through. To comprehend this phenomenon it must be remembered that with such a flow pattern are associated the pressure changes in the air which are the source of both lift and drag of the aerofoil. Pressure changes in any medium are not transmitted instantaneously, but with a finite velocity, and this velocity for pressure changes of the order of magnitude under consideration is approximately the speed of sound in air.

It follows, therefore, that if the aerofoil is travelling at or above the speed of sound (or sonic and supersonic velocity) it is robbed of any means of 'signalling' ahead. The air can no longer be prepared for its 


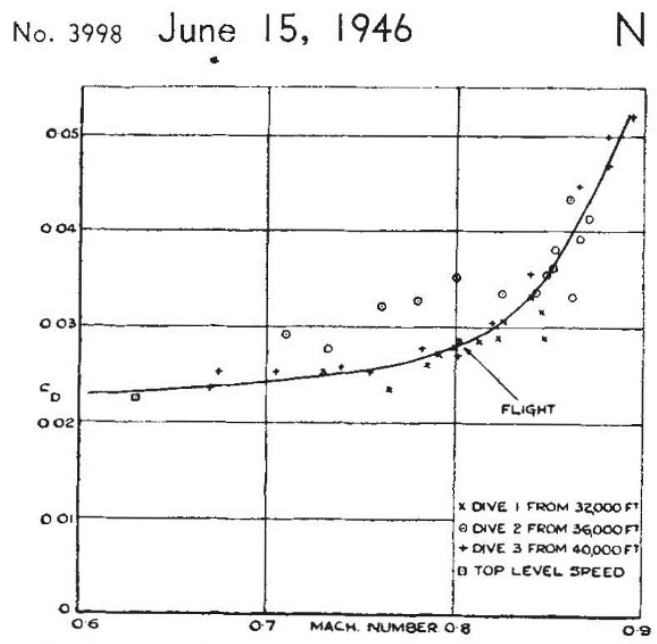

Fig. 1. Drag measurements in flight at high speed. Crown COPYRIGH'T RESERVED

arrival. The aerofoil can no longer slip through the air, which it now meets, inevitably head on, producing a shock wave which is the source of the largely increased drag. During the passage through a shock wave a certain amount of the mechanical energy content of the air is converted irreversibly, in a thermodynamic sense, to heat energy. This irrecoverable transformation of heat energy represents the work required to overcome the drag associated with the shock wave. If further there is separation behind the shock wave, thus producing a shock stall, the resultant eddying motion dissipates further energy.

The speed of sound in air varies as the square root of the absolute temperature and therefore decreases with altitude. It falls continuously from 760 m.p.h. at sea-level until the stratosphere is reached, where the speed is $660 \mathrm{~m} . \mathrm{p} . \mathrm{h}$. In the stratosphere, which extends from above $36,000 \mathrm{ft}$., the temperature, and therefore the speed of sound, is constant at about this figure. A given aircraft speed represents a higher fraction of the speed of sound at altitude than at sealevel ; and since this fraction is a significant factor in compressibility phenomena, it is convenient to speak of the Mach number, that is, the ratio of the forward velocity to the local velocity of sound, in dealing with the performance of high-speed aircraft.

Fig. 1 shows how the drag coefficient of the Spitfire varies with Mach number. The values at high Mach number have been obtained at the Royal Aircraft Establishment by steep diving at high altitudes. The highest Mach number recorded in these experiments was 0.92 , corresponding to a true aireraft speed of 620 m.p.h. at $31,000 \mathrm{ft}$. I should like here to pay a tribute to the experimental skill of those engaged in this work and to the superb flying qualities and courage of the pilots who cheerfully undertake this risky experimental flying. We have always been extremely fortunate in the happy working partnership of scientific workers and Service pilots, whose willing co-operation makes progress in aeronautical science possible.

Because of the acceleration of the air over certain parts of the structure, the aircraft velocity relative to air in these regions may reach the local velocity of sound, although the forward speed of the aircraft is below it. The Meteor, which recently won the world speed record, provided an interesting case of the same kind, where it was found from wind-tunnel tests that shock waves formed with subsequent breakaway of flow in the region of the maximum thickness of the engine nacelles. The consequent increase of drag and very severe buffeting would have limited the top speed to $565 \mathrm{~m} . \mathrm{p} . \mathrm{h}$. The problem consisted in reducing the acceleration of the air by diminishing the curvature of the surface, that is, by slimming the nacelle. The dimensions of the Derwent engine allowed no reduction of the diameter, and the only solution lay in lengthening the nacelle both fore and aft. This delayed the excessive drag rise and allowed a forward speed of more than 600 m.p.h. at sea-level. But for the largely increased drag due to the compressibility, the Meteor with the thrust of the Derwent engine would have reached a sea-level speed in level flight of 720 m.p.h.

Aeronautical science is largely occupied at the present time in overcoming the difficulties associated with the compressibility of air at high speeds. Three methods appear to be open for delaying the upward speed of the drag coefficient curve with Mach number. The first, as has already been indicated, lies in reducing curvature wherever possible, which leads to thin wings and slim nacelles and bodies.

The second lies in large sweep back of the wings. This important and significant advance in aerodynamie theory and practice for high-speed flight was made in Germany during the War. In its simplest form the theory indicates that for wings of infinite span an advantage in critical Mach number from $M$ to $M \sec \theta$ should be gained by a sweep back angle of $\theta$ from the square wing position. In fact, wind-tunnel experiments on high-speed swept-back wings show a possible gain of about half the theoreti. cal amount. But this, of course, is very considerable. Thus a sweep back of $40^{\circ}$ should, in aircraft of high subsonic speeds, allow an increase in forward speed of the order of 90 m.p.h. over that attainable with the square wing.

The third line of advance lies in small aspect ratio. The need for high aspect ratio wings is dictated in the subsonic region by the necessity to minimize induced drag. But at near sonic and supersonic speeds wings become almost free from induced drag, and structural engineers will no doubt rejoice in being free to design stubby wings for very high-speed aircraft.

These three lines of reasoning lead logically to a design of a high-speed aircraft resembling an arrowhead. In fact, a wind-tunnel model of an aircraft designed by Lippisch on these lines was recently found in Germany.

At supersonic speeds, shock waves govern everything. Any flying object has a well-developed shock wave at or near its forward end, and in the case of sharp-edged wings, a theory can be devised which allows forces and moments to be estimated, in very much the same way as for blunt-nosed wings at low subsonic speeds. Limitations on the use of wind tunnels for tests of wings disappear at about $M=1 \cdot 25$, and quite reasonable agreement between theory and experiment is found above this point. It is worth noting here that theory at supersonic speeds has not, so far, taken account of the viscosity of the air; but the frictional forces thereby neglected do not seem to be of importance compared with the effects of the pressure changes which occur with shock waves. Drag coefficients, for $M$ greater than about $1 \cdot 25$, decrease, though, of course, absolute values of drag continue to rise.

Flight at supersonic speeds introduces new problems in control. Supersonic aircraft must, at some period in their flight, pass from subsonic to supersonic conditions, and this produces a change from a more or less constant trim condition to another which is 
different but also more or less constant. The aerodynamic centre of a wing moves 25 per cent of the wing chord farther back, and in addition the tailplane suffers much less from the effects of the wing in front of it. The aircraft tends to become very much more stable. This means, unfortunately, that it is also much less mancuvrable; too much stability, for a craft required to be manœuvred rapidly in flight, is undesirable equally with too little.

A supersonic aircraft must therefore be designed to cope with both subsonic and supersonic aerodynamic regimes, and because of peak drag coefficient values which occur near Mach number 1 the transition between the two regimes will have to be accomplished as quickly as possible. There will also be a number of difficult ancillary problems to solve. The over-riding need for slimness in design will probably dictate the prone position for the pilot, desirable also on physiological grounds for withstanding high accelerations normal to the flight path, and we shall have to learn how to get the pilot clear in an emergency. Much intensive research will be necessary before human flight at supersonic speeds becomes possible. Supersonic aircraft are certainly not just round the corner.

\section{Power Plants}

Gas turbine. It is fortunate that at this moment in the evolution of aerodynamics, entirely new power plants capable of higher thrusts per unit cross-sectional area than the piston engine-a vital consideration in high-speed flying - should have been brought into being. Of these, the gas turbine with either propeller or jet propulsion (the latter is often called the 'turbo jet') is of the greatest present significance.

The two forms of propulsion by jet and propeller are characteristically different, but they are not different in principle. The propeller collects air, accelerates it by the action of its blades and discharges it to the rear. The turbo jet collects air through its intakes and, after burning it under pressure with fuel, discharges the resultant gases to the rear at high speed through a jet pipe. The propeller deals with much larger mass air flows but at lower discharge velocities than the turbo jet, and the efficiencies of the two means of propulsion vary according to forward speed (Fig. 2). At low aircraft speeds, the propeller is much the more efficient; but the efficiency of the jet increases rapidly with speed while that of the propeller falls. The jet begins to overhaul its rival at $600 \mathrm{~m} . \mathrm{p} . \mathrm{h}$. and at $700 \mathrm{~m} . \mathrm{p} . \mathrm{h}$. is well ahead. This coupled with the low frontal area of the gas turbine unit are the main reasons why the turbo jet is so eminently suitable for propulsion at high speeds.

At low speeds the turbo jet is much less economical in fuel consumption than the piston engine; but taking into account the lower specific weight of the gas turbine, the balance can be more than redressed by coupling the turbine engine to a propeller. It must be remembered that the gas turbine is in its infancy. Its future lies in higher compression ratios and higher working blade-temperatures. Intensive study is now being made of the design of aerofoils suitable for use in compressors operating at high speeds. These studies are in the first place made in wind tunnels particularly designed to give us know. ledge of the flow through a row of blades. They are called 'cascade tunnels' from the arrangement of blades in a cascade. The next step in the work is to study the flow in a single-stage compressor, and the final experiments are done on a multi-stage compres. sor.

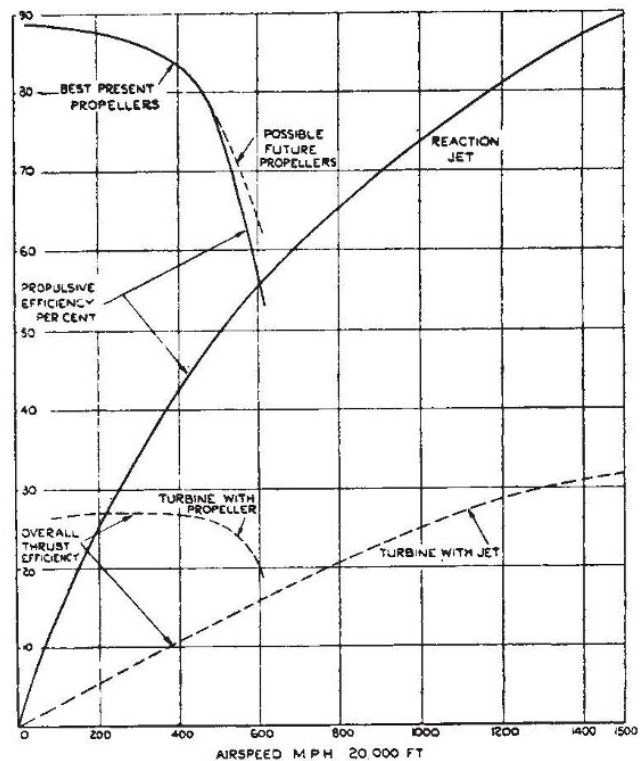

Fig. 2. COMPARATIVE PROPULSIVE AND OVERALL THRUST EFFICIENCIES. CROWN COPYRIGHT RESERVED

This work will undoubtedly result in the near future in axial flow compressors having high efficiency and double the present compression ratio.

The efforts of metallurgists should enable working blade-temperatures to be raised well above the present level of about $700^{\circ} \mathrm{C}$. to about $900^{\circ} \mathrm{C}$. in the course of the next fow years. Blade cooling may enable gas working temperatures to be raised higher still. The Germans worked on this because of their shortage of suitable materials, and at one German research institute a gas turbine with water-cooled blades has been run with a temperature of $1,200^{\circ} \mathrm{C}$.

Propulsive duct. At supersonic speeds the total head pressure at the entry duct becomes so high that a compressor becomes superfluous. At 1,250 m.p.h. at sea-level (Mach number 1.65), for example, the total head pressure is about $59 \mathrm{lb}$. per sq. in., corresponding to the compression ratio of about $4: 1$ of existing turbo jets. Since a turbine is only necessary to drive the compressor, the turbine becomes superfluous also. This leads directly to the simple conception of a shaped tube, called a propulsive duct, without any moving parts, as a power unit for supersonic flight. Air is encountered at supersonic velocity and is reduced to subsonic velocity through a shock. wave entry before reaching the combustion chamber. The shock loss at entry varies with Mach number. The duct is designed to allow a speed of about a tenth that of the aircraft velocity through the combustion chamber, where fuel is burned under conditions of constant pressure. The burnt gases are then ejected through the jet pipe. The thermodynamic cycle is thus precisely similar to that of the turbo jet. At low speeds the propulsive duct is, of course, very inefficient, and some form of boost is required to accelerate the speed to a sufficiently high value at which the propulsive duct can operate economically.

Liquid rocket motor. The third type of power unit likely to prove of great value in aircraft p ropulsion is the liquid rocket motor, the characteristic feature of which is that, unlike the power units already described, the oxygen for combustion is not drawn from the surrounding atmosphere but is self-contained within the fuel. The main advantages of the rocket 
motor are: (i) its comparative simplicity and cheapness ; (ii) the high thrust per unit area of combustion chamber cross-section that can be obtained-10,000 to $30,000 \mathrm{lb}$. per sq. ft. are common; and (iii) the maintenance of approximately constant thrust with altitude; this is peculiar to the rocket motor and is of particular significance in obtaining high rates of climb at high altitudes.

But, of course, a heavy price has to be paid for these characteristics. The rocket motor burns fuel extravagantly to provide the maximum possible thrust. Its specific fuel consumption is very high, about 15-20 lb. of fuel being consumed per hour per pound of thrust, as compared with a corresponding figure of $1-3 \mathrm{lb}$. for the various air-consuming systems. This type of propulsion is best suited for special purposes, for example, for assisted take-off for aircraft, for increasing the performance of interceptor aircraft during the climb and during combat, or for boosting aircraft from the subsonic to the supersonic range.

The rocket motor has been developed to a remarkable degree of excellence by Dr. Walter of Kiel in Germany, one of whose motors formed the power unit of the interceptor fighter Me. 163, which represents the only example to date of an aircraft powered solely by a rocket motor. The design is interesting as embodying the large sweep back, shortened body and absence of conventional tail unit, advantages for high-speed flight which have already been mentioned.

The specific impulse of the rocket motor, defined as thrust in lb. produced per unit rate of burning (l lb. per sec.), is proportional to $(a)$ the square root of the ratio of the absolute temperature of the gases before expansion to the molecular weight of the jet mixture, and $(b)$ to a term involving the ratio of specific heats and expansion ratio. Term $(b)$ is relatively constant for all fuel and design systems. The temperature/molecular weight ratio is thus the important variable, and the highest possible combustion temperature and the lowest molecular weight are required. The temperature is seriously limited by the material of the chamber walls : combustion temperatures of $2,000-3,000^{\circ} \mathrm{C}$. are encountered at present, and metallurgical and chemical calculations make it unlikely that in the foreseeable future these temperatures can be raised appreciably. The main hope of improving the specific impulse therefore lies in the lowering of the molecular weight.

The molecular weights of present-day jet gases are in the neighbourhood of 20 , and apart from hydrogen and helium there are no other gases, suitable at high temperatures, which have significantly lower molecular weights. A liquid oxygen-liquid hydrogen system could give a specific impulse about 50 per cent higher than that of the best fuels now used. But apart from difficulties of handling, the most serious drawback of this system is the low density of liquid hydrogen, which leads to a considerable increase in 'dead' weight for the same weight of fuel. Fuel density is an important secondary consideration of efficiency. Indeed it is found that in most applications this fact more than offsets the higher specific impulse, and it is generally agreed that fuel systems with significantly greater specific impulses than those in use are not likely to come into practical operation in the foreseeable future.

Comparisons of new types of propulsion. The efficiencies of these new types of propulsion, expressed in terms of thrust h.p. per weight of fuel consumed per hour and forward speed at $36,000 \mathrm{ft}$. and above, are shown in Fig. 3. With the exception of the rocket

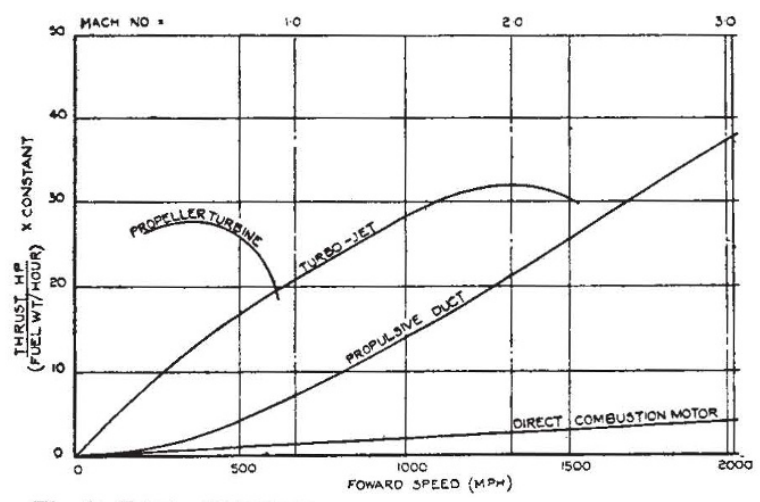

Fig. 3. POWER PLANT EFFICIENCY COMPARISON FOR AN ALTITUDE

OF 36,000 FT. AND ABOVE. CROWN COPYRIGHT RESERVED

motor, each type of power plant possesses a dominating advantage over a particular speed-range. Thus the propeller turbine holds the field up to about 600 m.p.h. The turbo jet takes over from this speed to about 1,600 m.p.h., when the superior efficiency of the propulsive duct asserts itself. The rocket motor makes a poor showing on this diagram, but, as has already been explained, its usefulness is based on other grounds than efficiency.

\section{Helicopters}

So far we have only considered aircraft which derive their lift from stationary wings, but the first attack on the problems of flight, long before this was mechan. ically possible, was in imitation of the bird. Flapping and rotating wings were the object of detailed study so far back as the fourteenth century, and Leonardo da Vinci left several valuable and interesting sketches of an aircraft-like machine with lifting screws rotating about a vertical axis, now called a helicopter.

An aircraft of this type which will rise vertically from the ground, hover, descend vertically, either at will or in the event of engine failure, and fly hori. zontally at a reasonable speed possesses obvious attractions. It also presents many obvious aerodynamic and mechanical difficulties. Several types of aircraft designed to solve these problems have been worked at, on and off, during the last twenty years, but it was not until Sikorsky built his helicopter in America during the War that a widespread interest in helicopters was aroused. Three German experimental types, the Focke, Flettner and Doblhoff, have also flown successfully.

To maintain safety the rotor blades must, in the event of engine failure, autorotate without stalling. This condition becomes increasingly difficult to sustain as the forward speed increases. The forward thrust in the helicopter is obtained by tilting the rotor disk forward with respect to the flight path, and an increase of forward speed entails an increase in axial flow through the rotor. This results in a reduced blade angle of attack, which in turn demands an increase in blade angle, generally greater at high forward speeds than the maximum value at which the rotor would autorotate in unpowered flight. Engine failure therefore calls for a very rapid alteration of the pitch of the blades. Automatic means for doing this will no doubt be introduced in the future, and any such mechanism must take account of the fact that changes in axial flow through the rotor do not alter the blade angle of attack equally along the span, the tip being least affected.

With the present designs of helicopters, a 
height of 50-100 ft. from the ground is a dangerous one in the event of engine failure during hovering flight. This is because stoppage of the power, followed by autorotation of the blades, changes the direction of airflow through the rotor disk from downwards to upwards. It takes time to change the state of flow, and during the process height is lost and a large vertical velocity is gained. For disk loadings of present helicopters, of the order of $2 \frac{1}{4} \mathrm{lb}$. sq. $\mathrm{ft}$., the loss of height would be about $100 \mathrm{ft}$. and the vertical velocity $30 \mathrm{ft}$. per second. The helicopter under these conditions can only be landed safely if a special undercarriage is provided to absorb the energy of descent; this cannot be achieved except at the expense of increased structure weight.

The problem can be dealt with in three ways : (i) by reducing the disk loading; (ii) by increasing the mass of the rotor, so increasing the amount of stored energy ; (iii) by putting excess power into the rotor, another means of increasing the stored energy. All these solutions present difficulties, but it is very likely that one of them or a combination will be used in future designs.

In all helicopters in which the blades are driven by externally applied power, the rotor torque must be balanced out. In the Sikorsky helicopter a small auxiliary rotor driven from the engine and located at the tail gives thrust at right-angles to the line of flight. An alternative solution to this problem lies in using a pair of rotors rotating side by side in opposite senses, as in the Focke helicopter.

In the Flettner helicopter, intended for shipborne operation, there are two intermeshing bladed rotors, the two drive shafts having an included angle of $24^{\circ}$, and the centres of the two hubs being about $2 \mathrm{ft}$. apart. Longitudinal and lateral control is obtained by joint cyclic pitch change of the two rotors. Yawing control is by a combination of rudder and differential pitch control of the two rotors. A blade pitch governor is provided which holds the rotor revolutions per minute (r.p.m.) constant within certain limits, the lower limit being the safe r.p.m. in the case of engine failure.

The Doblhoff type is an experimental single-seater helicopter, in which a single rotor is driven by jets on the blade tips. There is, of course, no torque to be balanced out in this case. An aircraft engine is used to drive a supercharger, and the compressed air is mixed with fuel which is metered to maintain the correct fuel/air ratio. The combustible mixture is ducted to the hub and out through the three blades where it is burnt in combustion chambers at the blade tips. The fuel consumption is, of course, very high, and it was the intention of the inventor only to use the jets for relatively short periods for hovering, takeoff and landing, translational flight being obtained by reverting to the auto-rotational regime, for which purpose a pusher propeller could be clutched to the engine.

The possibilities in an aircraft which is not tied to specially prepared aerodromes and can land and take off from any clear space slightly bigger than its own dimensions are obviously far-reaching. The helicopter will probably become the air taxi of the future, transporting passengers from the main airports, situated outside towns because of their very large size, to town centres. Large stores, clubs and office blocks will doubtless provide themselves with flat roofs for the landing of helicopters, and it may be expected that the helicopter will eventually be used on a large scale for private flying.

\section{THE MULTIPLICITY OF FORAMINA MENTALIA IN A HUMAN MANDIBLE FROM THE COPPER AGE OF ANATOLIA}

\section{By Prof. MUZAFFer SÜLEYMAN SENYÜREK University of Ankara}

$\mathrm{D}^{\mathrm{T}}$ URING the course of an investigation on ancient Anatolian crania, I found a mandible with four or five foramina instead of a single foramen mentale. I am reporting it here as it is a very rare case, if not indeed the first one, reported for Homo sapiens. In fact, Prof. F. Weidenreich ${ }^{1}$ in his exhaustive monograph on the mandibles of Sinanthropus pekinensis (p. 29) quotes Simonton to the effect that "four or five foramina have never been found in recent man regardless of race". The same author also cites Akabori as never having observed four or five foramina among the Japanese.

The mandible under discussion (Kusura No. V.94.76) is from the copper period of Kusura, a site near Afyonkarahisar excavated by Miss Winifred Lamb, and is preserved in the Department of Anthropology of the University of Ankara. On the right side of the corpus mandibulæ (Fig. 1, $b$ ) ${ }^{*}$ there are five foramina located in a well-defined depressed area of oval shape. The line connecting the lower boundaries of the foramina forms a curve, with convexity toward the
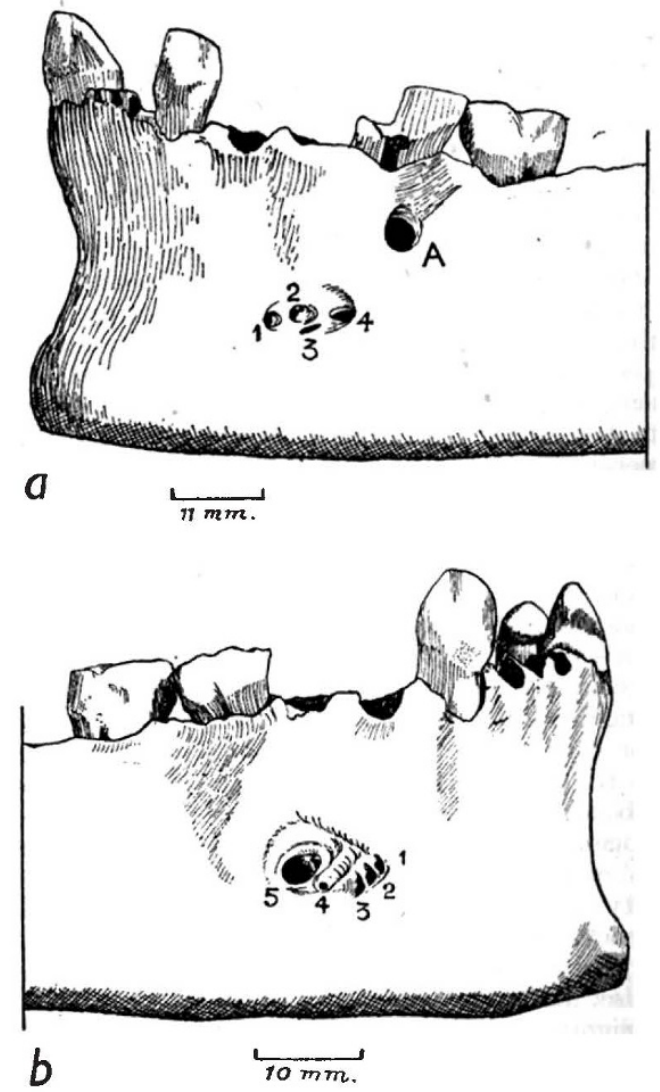

Fig. 1. MANDIble From Kusura (No. V.94.76), NEAR AFyoN KARAHISAR, TURKEY. $a$, LEET SIDE ; $b$, RIGHT SIDE OF MANDIBLE, THE FORAMINA ARE SHOWN BY NOMBERS 1-5. THE LARGE HOLE, $A$, IN UPPER FIGURE IS NOT A FORAMEN, BUT IS DOE TO A BADLY ABSCESSED FIRST MOLAR

* I am grateful to my colleague, Prof. W. J. McCallien, for the illustrations accompanying this article. 